\title{
Nicotine Self-Administration Induces CB1-Dependent LTP in the Bed Nucleus of the Stria Terminalis
}

\author{
Anne-Ruth Reisiger, ${ }^{1,2}$ Jennifer Kaufling, ${ }^{6,7}$ Olivier Manzoni, ${ }^{3,4,5}$ Martine Cador, ${ }^{1,2}$ François Georges, ${ }^{6,7 *}$ \\ and Stephanie Caillé ${ }^{1,2 *}$ \\ ${ }^{1}$ Université de Bordeaux, INCIA, BP31, F-33076 Bordeaux, France, ${ }^{2}$ Centre National de la Recherche Scientifique, UMR5287 INCIA, F-33076 Bordeaux, \\ France, ${ }^{3}$ INSERM U901, F-13009 Marseille, France, ${ }^{4}$ Université de la Méditerranée UMR S901, Aix-Marseille 2, France, ${ }^{5}$ INMED, F-13009 Marseille, France, \\ ${ }^{6}$ Université de Bordeaux, Interdisciplinary Institute for Neuroscience, UMR5297, F-33000 Bordeaux, France, and ${ }^{7}$ Centre National de la Recherche \\ Scientifique, Interdisciplinary Institute for Neuroscience, UMR5297, F-33000 Bordeaux, France
}

Nicotine addiction is characterized by repetitive drug taking and drug seeking, both tightly controlled by cannabinoid CB1 receptors. The responsiveness of neurons of the bed nucleus of the stria terminalis (BNST) to infralimbic cortex (ILCx) excitatory inputs is increased in rats with active, but not passive, nicotine taking. Therefore, we hypothesize that acquisition of the learned association between nicotine infusion and a paired cue light permits the strengthening of the ILCX-BNST synapses after ILCx tetanic stimulation. We exposed rats to intravenous nicotine self-administration for 2 months. Using a combination of in vivo protocols (electrical stimulations, extracellular recordings, and pharmacological manipulations), we characterized the effects of $10 \mathrm{~Hz}$ stimulation of the ILCx on BNST excitatory responses, under different conditions of exposure to nicotine. In addition, we tested whether the effects of the stimulation were CB1 receptor-dependent. The results show that nicotine self-administration supports the induction of evoked spike potentiation in the BNST in response to $10 \mathrm{~Hz}$ stimulation of ILCx afferents. Although not altered by nicotine abstinence, this cellular adaptation was blocked by CB1 receptor antagonism. Moreover, blockade of BNST CB1 receptors prevented increases in time-out responding subsequent to ILCx stimulation and decreased cue-induced reinstatement. Thus, the synaptic potentiation within the BNST in response to ILCx stimulation seems to contribute to the cue-elicited responding associated with nicotine self-administration and is tightly controlled by $\mathrm{CB} 1$ receptors.

Key words: addiction; bed nucleus of the stria terminalis; $\mathrm{CB} 1$ receptor; in vivo electrophysiology; intravenous self-administration; nicotine

\section{Introduction}

The ventromedial prefrontal cortex (infralimbic cortex [ILCx] in rodents) is involved in behavioral inhibition, attentional processes, and goal-directed behaviors (Smith et al., 2012), suggesting a crucial role in drug-related behaviors, such as learning and relapse (Peters et al., 2009; Lüscher and Malenka, 2011). Furthermore, the ILCx sends major excitatory projections to the bed nucleus of the stria terminalis (BNST) (Massi et al., 2008), a structure responsive to drug rewards (Carboni et al., 2000; Dumont et al., 2005; Krawczyk et al., 2013). In agreement with these

Received July 25, 2013; revised Feb. 4, 2014; accepted Feb. 13, 2014.

Author contributions: F.G. and S.C. designed research; A.-R.R., J.K., F.G., and S.C. performed research; A.-R.R., F.G., and S.C. analyzed data; A.-R.R., O.M., M.C., F.G., and S.C. wrote the paper.

This work was supported by Centre National de la Recherche Scientifique, University of Bordeaux, Agence Nationale de la Recherche ANR-2010-BLAN-1439-01 to S.C. and F.G., and Region Aquitaine. We thank Florence Darlot, Emilie Noe, and Delphine Girard for technical assistance; Drs. Cyril Herry, Giovanni Marsicano, and Francis Chaouloff for valuable comments on the manuscript; and Julia Slone-Murphy (www.neuroedit.com) for editorial assistance. The authors declare no competing financial interests.

${ }^{*}$ F.G. and S.C. contributed equally to this work.

Correspondence should be addressed to either of the following: Dr. Stephanie Caillé-Garnier, Université de Bordeaux, INCIA, BP31, F-33076 Bordeaux, France, E-mail: stephanie.garnier@u-bordeaux2.fr; or François Georges, Université de Bordeaux, Interdisciplinary Institute for Neuroscience, UMR5297, F-33000 Bordeaux, France, E-mail: francois.georges@u-bordeaux.fr.

DOI:10.1523/JNEUROSCI.3149-13.2014

Copyright $\odot 2014$ the authors $\quad 0270-6474 / 14 / 344285-08 \$ 15.00 / 0$ findings, we previously showed that the hyperactivity of VTA dopamine neurons after extended nicotine taking is driven by changes in the ILCx-BNST excitatory afferent circuit to the VTA (Caillé et al., 2009). However, it is not known whether ILCxBNST synapses are more prone to developing synaptic plasticity subsequent to the acquisition of nicotine self-administration behavior. The first aim of our study was to investigate whether the stimulation of ILCx inputs at physiologically relevant frequencies could reveal cellular adaptations at ILCX-BNST synapses in rats trained to self-administer nicotine. Thus, at different time points of nicotine self-administration training, $10 \mathrm{~Hz}$ stimulation of the ILCx (Jackson et al., 2001) was applied and in vivo recordings were performed in the BNST. Based on the hypothesis that longterm adaptations of synapses may support persistent drug seeking, we also investigated whether the effect of ILCx stimulation on ILCx-BNST synapses would resist either extinction or 1 month of abstinence to nicotine. Moreover, a challenging question was whether the LTP protocol imposed on the glutamatergic ILCx projection to the BNST had consequences on operant behavior for nicotine and nicotine-paired cues. Finally, cannabinoid $\mathrm{CB} 1$ receptors play an important role in nicotine-related behaviors (Maldonado et al., 2006; Simonnet et al., 2013), and blocking CB1 receptors has been proposed for the treatment of nicotine addiction (Le Foll et al., 2008). Preclinical studies have 
demonstrated that CB1 knock-out mice do not develop nicotineinduced hyperactivity (Castañé et al., 2002) or nicotine-induced conditioned place preference (Castañé et al., 2002; Merritt et al., 2008). CB1 receptor antagonism has been shown to decrease nicotine self-administration (Cohen et al., 2002) as well as nicotine seeking (Cohen et al., 2005; Shoaib, 2008). Importantly, CB1 receptors in the BNST control cortical excitation of BNST neurons (Massi et al., 2008). Therefore, we also tested whether the neuroplastic changes characterized at ILCx-BNST synapses and their effect on nicotinerelated behaviors were modulated by $\mathrm{CB} 1$ receptors.

\section{Materials and Methods}

\section{Animals}

Male Sprague Dawley rats weighing 175-200 g (Charles River) were housed collectively at $20^{\circ} \mathrm{C}-22^{\circ} \mathrm{C}$ with a reversed $12 \mathrm{~h}$ light/dark cycle (lights off from 9:30 A.M.). One week before the start of the experiment, rats were placed on a restricted diet of $20 \mathrm{~g} / \mathrm{d}$ laboratory chow, sufficient to maintain body weight and growth. Water was available ad libitum, and food was given daily after the self-administration session. All procedures were conducted in accordance with the European Directive 2010-63-EU on the protection of animals used for scientific purposes and with approval of the Bordeaux University Animal Care and Use Committee (\# 5012058-A).

\section{Surgery}

Intravenous surgery was performed under anesthesia with ketamine (75 $\mathrm{mg} / \mathrm{kg}$ ) and xylazine (7.5 mg/kg) (i.p.). Chronic indwelling jugular catheters were implanted as described previously (Caillé et al., 2009). During postoperative recovery, catheters were flushed daily with $0.2 \mathrm{ml}$ ampicillin $(0.1 \mathrm{~g} / \mathrm{ml}$; Coophavet) in heparinized saline ( $300 \mathrm{IU}$ heparin per $\mathrm{ml} 0.9 \% \mathrm{NaCl}$ ) for $6 \mathrm{~d}$. Subsequently, catheters were flushed daily with heparinized saline. Catheter patency was verified with an infusion of the short-acting barbiturate hypnomidate ( $2 \mathrm{mg} / \mathrm{ml}$, Janssen-Cilag), when necessary.

Stereotaxic surgery for in vivo electrophysiology experiments was performed under isoflurane anesthesia as described previously (Georges and Aston-Jones, 2002). Stimulation electrodes and recording and injection pipettes were inserted into the ILCx or BNST at the following coordinates (Paxinos and Watson, 1998): ILCx: $3.0 \mathrm{~mm}$ from bregma, $0.5 \mathrm{~mm}$ from midline, $4.5 \mathrm{~mm}$ from brain surface; BNST: $-0.3 \mathrm{~mm}$ from bregma, 1.5 $\mathrm{mm}$ from midline, $6.0-7.5 \mathrm{~mm}$ from brain surface.

\section{Drugs}

Nicotine hydrogen tartrate salt (Sigma-Aldrich) and AP5 (Sigma Aldrich) were dissolved in sterile $0.9 \%$ saline and stored at room temperature. The CB1 receptor antagonists O-2050 (Tocris Bioscience) and AM251 (Tocris Bioscience) were dissolved in a vehicle containing ethanol (Sigma-Aldrich), cremophor (Sigma-Aldrich), and saline at a ratio of $1: 1: 18$, and stored at $4^{\circ} \mathrm{C}$. Nicotine (30 and $\left.60 \mu \mathrm{g} / \mathrm{kg} / 0.1 \mathrm{ml}\right)$, AM251 (2 $\mathrm{mg} / \mathrm{kg})$, and $\mathrm{O}-2050(0.5 \mathrm{mg} / \mathrm{kg})$ were infused intravenously. AM251 $(400 \mu \mathrm{M})$ and AP5 $(100 \mu \mathrm{M})$ were microinjected into the BNST using brief pulses of pneumatic pressure (Picospritzer; General Valve).

\section{Intravenous nicotine self-administration}

Experiments started at the beginning of the dark phase. Rats were tested in standard operant chambers (Imetronic) equipped with two nose-poke detectors ("active" and "inactive"). Daily $2 \mathrm{~h}$ self-administration sessions started with illumination of the house light and a single noncontingent infusion. "Active" nose-poking resulted in the delivery of a nicotine infusion $(30 \mu \mathrm{g}$ base $/ \mathrm{kg} / 100 \mu \mathrm{l}$ first, increasing to $60 \mu \mathrm{g}$ base $/ \mathrm{kg} / 100 \mu \mathrm{l}$ when stabilized on FR5) or saline over $4 \mathrm{~s}$. Each infusion was paired with a cue-light for $4 \mathrm{~s}$ and followed by a $20 \mathrm{~s}$ time-out period during which visits to the active nose-poke hole were recorded but had no consequences. "Inactive" nose-pokes were recorded but had no programmed consequences. Infusions were earned on a fixed-ratio (FR) schedule of reinforcement (10 d FR1; 2 d FR2; stabilizing on FR5). Selfadministration chambers were equipped with infrared activity detectors, allowing general activity measures (number of beam breaks) when necessary.

Extinction and reinstatement. Extinction commenced by removal of nicotine delivery and associated cue-light, and continued for $2 \mathrm{~d}$. Rein- statement testing started with $30 \mathrm{~min}$ no cue/no nicotine presentation, immediately followed by a $30 \mathrm{~min}$ period during which "active" nosepokes resulted in illumination of the nicotine associated cue-light but nicotine remained unavailable. Thus, seeking behavior was measured by the number of visits to the active hole.

\section{Oral saccharin self-administration}

Experiments started at the beginning of the dark phase. Rats were tested in standard operant chambers for at least 6 weeks, as described above. Daily 30 min sessions started with illumination of the house light. "Active" nose-poking resulted in the delivery of $112 \mu \mathrm{l}$ of saccharin $0.13 \%$ (Sigma-Aldrich) over $4 \mathrm{~s}$. Each reinforcer was paired with a cuelight for 4 s. "Inactive" nose-pokes were recorded but had no programmed consequences. Reinforcers were earned on an FR schedule (10 d FR1; 2 d FR2; stabilized on FR5).

\section{Electrical stimulation of the ILCX}

Bipolar electrical stimulation of the ILCx was conducted with a concentric electrode (Phymep) and a stimulus isolator (500 $\mu \mathrm{s}, 0.2-1 \mathrm{~mA}, \mathrm{DS} 3$; Digitimer). First, a $10 \mathrm{~min}$ baseline was established when recording evoked spikes in the BNST during a $2 \times 100$ pulse train $(0.5 \mathrm{~Hz})$, after which tetanic stimulation was performed $(1 \mathrm{~min}, 10 \mathrm{~Hz})$.

\section{BNST recordings and pharmacological microinfusion}

Extracellular single-unit recordings were used for electrophysiological experiments. A glass micropipette (tip diameter, $1-2 \mu \mathrm{m} ; 10-15 \mathrm{~m} \Omega$ ) filled with a $2 \%$ pontamine sky blue solution in $0.5 \mathrm{~m}$ sodium acetate was lowered into the BNST. The extracellular potential was recorded with an Axoclamp2B amplifier and filtered $(300 \mathrm{~Hz} / 0.5 \mathrm{kHz})$ via a differential AC amplifier (Georges and Aston-Jones, 2002). Single-neuron spikes were discriminated and collected online (CED 1401, SPIKE 2; Cambridge Electronic Design).

Double-barreled pipettes (Georges and Aston-Jones, 2002) were used to record BNST activity while microinjecting drugs. A total volume of 60 $\mathrm{nl}$ was infused into the BNST, using pneumatic pressure (Picospritzer; General Valve). One minute after microinfusion into the BNST, the ILCx was electrically stimulated for $1 \mathrm{~min}$ at $10 \mathrm{~Hz}$. Post-tetanic evoked responses were recorded for at least $20 \mathrm{~min}$ while stimulating the ILCx (100 pulses; $0.5 \mathrm{~Hz}$ ).

\section{Experimental design}

Nicotine-dependent LTP induction in the BNST. The first aim here was to determine the conditions under which $10 \mathrm{~Hz}$ stimulation of the ILCX would induce LTP within the BNST. Moreover, the stimulation protocol was run at several time points to examine whether the experimenterinduced LTP was correlated with the acquisition of nicotine selfadministration (see Fig. 1A). We used five groups of rats: (1) single session (NIC-1 d, $n=5$ ); (2) eight sessions (NIC-8 d, $n=8$ ); (3) extended training for nicotine (NIC-60 d, $n=8$ ); (4) extended training for saline (SAL-60 d, $n=6$ ); and (5) nicotine yoked rats $(n=5)$, in which nicotine infusions were matched to those of NIC-60 d rats, so that yoked rats never controlled the nicotine delivery associated with the visual stimulus. A last control group, trained for oral saccharin $0.13 \%(n=5)$, was added to show that the electrical stimulation of ILCx induced LTP specifically in the BNST of nicotine-taking rats. Electrophysiological recordings were performed $24 \mathrm{~h}$ after the last access to the operant chambers.

Persistence of induced LTP in the BNST. We examined whether the neuroadaptations of ILCX-BNST synapses were sensitive to passive abstinence or to active suppression of acquired responses (extinction training). A group of animals was trained for nicotine selfadministration for $60 \mathrm{~d}$. Half of the group (Abst, $n=7$ ) was confined to home cages for $30 \mathrm{~d}$, until electrophysiological recordings were performed. The other half (Ext, $n=6$ ) performed extinction training where active nose-poking had no programmed consequences: no drug delivery and no cue presentation. For each rat, extinction training took place until the active responding level was $30 \%$ of baseline (for 3 consecutive days); then electrophysiological recordings were performed $24 \mathrm{~h}$ after the last extinction session.

Characterization of induced LTP in the BNST. NMDA-dependent plasticity. Rats received $60 \mathrm{~d}$ of nicotine self-administration training. Twenty-four 
A

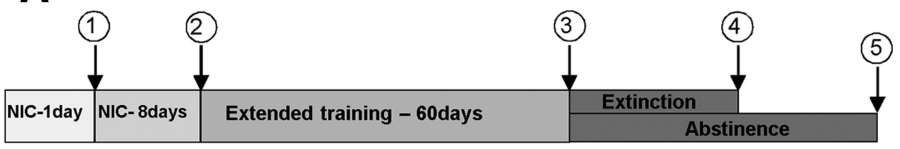

B

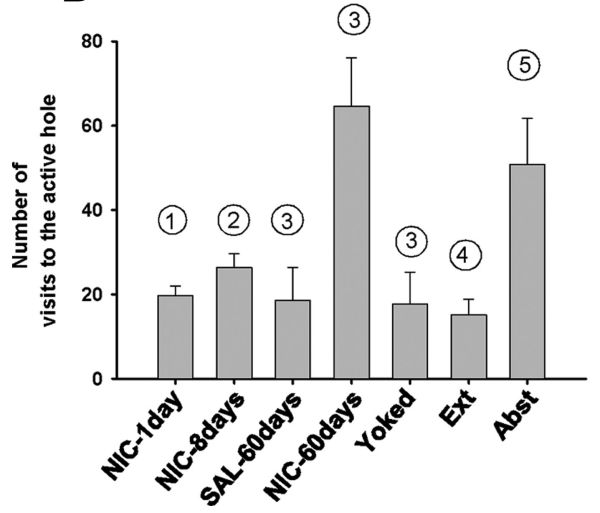

C

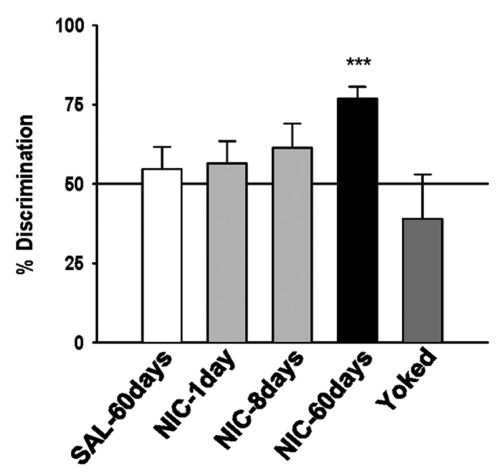

Figure 1. Operant behavior before electrophysiological recordings. $A$, Timeline of experiment. Animals were recorded $24 \mathrm{~h}$ after the following: (1) a single nicotine self-administration session (NIC-1 d, $n=5$ ), (2) eight sessions of nicotine self-administration (NIC-8 d, $n=8$ ), (3) extended training (NIC-60 d, $n=8$; SAL-60 d, $n=7$; yoked, $n=5$ ), (4) extinction (Ext, $n=6$ ), or (5) abstinence (Abst, $n=7$ ). $\boldsymbol{B}$, Number of visits in the active hole. Each bar represents the average number over the 3 last days before electrophysiological recording for each experimental group (except the "1 day" group). C, NIC-60 d rats showed a strong preference for the active hole. ${ }^{* * *} p<0.001$. Data are mean + SEM.

hours after the last session, each rat was subjected to in vivo electrophysiology. One minute before tetanic stimulation, either the NMDA receptor antagonist AP5 (NIC-60 d+AP5, $100 \mu \mathrm{M}, 60 \mathrm{nl}, n=5$ ) or saline vehicle (NIC-60 d+Veh, $60 \mathrm{nl} ; n=8$ ) was microinfused into the BNST.

CB1 receptor-dependent plasticity. Rats received $60 \mathrm{~d}$ of nicotine selfadministration training and were recorded $24 \mathrm{~h}$ after the last session. Three groups were tested, with each rat receiving an intravenous injection of either AM251 (NIC-60 d+AM251, $n=5$ ), O-2050 (NIC-60 $\mathrm{d}+\mathrm{O}-2050, n=4)$, or vehicle (NIC-60 d+Veh, $n=3) 60 \mathrm{~min}(\mathrm{O}-2050)$ or $15 \mathrm{~min}$ (AM251 or vehicle) before tetanic stimulation.

Two additional groups were tested with intra-BNST infusion of AM251 (NIC-60 d+AM251, $n=5$ ) or vehicle (NIC-60 d+Veh; $n=5$ ).

Effect of electrical stimulation of the ILCX on nicotine taking (selfadministration) and nicotine seeking (cue-induced reinstatement): control by $C B 1$ receptors. Rats received $60 \mathrm{~d}$ of nicotine self-administration training. Twenty-four hours after the last self-administration session, electrodes were bilaterally inserted into the ILCX as described above. Electrical stimulation $(1 \mathrm{~min}, 10 \mathrm{~Hz}$ ) was administered once, using a square pulse stimulator and stimulus isolator (DS3; Digitimer). One minute before tetanic stimulation, rats received an intra-BNST infusion $(60 \mathrm{nl})$ of either AM251 (400 $\mu \mathrm{M}, n=13)$ or vehicle $(n=13)$. Control groups received the same protocols with sham stimulation (vehicle, $n=$ 8 ; AM251, $n=7$ ). After a $48 \mathrm{~h}$ recovery period, rats were placed back in the operant cages and nicotine self-administration was monitored for four consecutive sessions. Then rats from the group stimulated (AM251, $n=8$; Veh, $n=8$ ) and the group sham stimulated (AM251, $n=7$; Veh, $n=8$ ) performed extinction training for $2 \mathrm{~d}$ and were tested for cueinduced reinstatement on the third day (Deroche-Gamonet et al., 2004).

\section{Data analysis}

Behavioral data. Nicotine self-administration data were subjected to ANOVAs, with nicotine exposure (NIC-1 d, NIC-8 d, NIC-60 d, yoked, saline) or saccharin exposure as the between-subject factor and selfadministration session as the within-subject factor. For reinstatement data, between-subjects factors were the treatment with the CB1 antagonist (vehicle or AM251) and the stimulation of the ILCX (sham or stim). Whenever main factor effects were found, post hoc comparisons were performed using Fisher's protected least significant difference test. The discrimination rate $([$ active nose-pokes/total nose-pokes] $\times 100)$ was compared with chance (50\%) with Student's $t$ test. Statistical significance was set at $p<0.05$.

Electrophysiological recordings. During electrical stimulation of the ILCx, cumulative peristimulus time histograms ( $5 \mathrm{~ms}$ bin width) of evoked-spike activity were generated for each neuron recorded in the BNST. Peristimulus time histograms were analyzed to determine excitatory epochs as described previously (Georges and Aston-Jones, 2002). Excitatory magnitudes ( $R_{\text {mag }}$ values) were normalized for different levels of baseline impulse activity, allowing comparison of effects of stimulus intensity on evoked responses independent of those on baseline activity. $R_{\text {mag }}$ values for excitation were calculated using the following equation: Excitation $\mathrm{R}_{\mathrm{mag}}=$ (counts in excitatory epoch) - (mean counts per baseline bin $\times$ number of bins in excitatory epoch). For multiple comparisons, values were subjected to a oneway ANOVA followed by Bonferroni post hoc analysis. Where two means were compared, the two-tailed paired Student's $t$ test was used.

\section{Results}

Acquisition of nicotine selfadministration in rats allows the induction of LTP at ILCX-BNST synapses in response to $10 \mathrm{~Hz}$ stimulation of the ILCX

Rats had access to nicotine selfadministration by nose-poke operant responding ( $60 \mu \mathrm{g}$ base $/ \mathrm{kg} /$ $0.1 \mathrm{ml}$ ) for $1 \mathrm{~d}(\mathrm{NIC}-1 \mathrm{~d}), 8 \mathrm{~d}$ (NIC-8 d), or $60 \mathrm{~d}$ (NIC-60 d; timeline, Fig. $1 A$ ). Control rats were trained with saline (SAL-60 d), and the volitional aspect was examined using a yoked group (Palmatier et al., 2007). Depending on drug access, rats developed different levels of responding for the active nose-poke (Fig. $1 B)$. NIC-60 d rats developed robust nicotine intake with good discrimination between the "active" and "inactive" holes (Fig. $1 C$; one-way ANOVA, $F_{(3,21)}=4.28, p<0.05$; discrimination rate vs chance, $\left.t_{(7)}=7.33, p<0.001\right)$. At the end of the 2 month training period, NIC-60 d and yoked rats had similar total nicotine intake (NIC-60 d, $31.75 \pm 1.63 \mathrm{mg} / \mathrm{kg}$; yoked, $36.30 \pm 4.74$ $\mathrm{mg} / \mathrm{kg}$ ). In vivo electrophysiological extracellular single-unit recordings of BNST neurons were performed $24 \mathrm{~h}$ after the last self-administration session. Evoked spike potentiation in response to electrical stimulation of the ILCx ( $1 \mathrm{~min}, 10 \mathrm{~Hz}$; Fig. $2 A, B)$ in NIC-60 d rats was greater than in all other conditions of exposure (Fig. 2C,D; two-way ANOVA, interaction time $\times$ treatment, $F_{(36,153)}=1.60, p=0.02$; effect of treatment, $F_{(4,17)}=4.87$, $p=0.008)$. The average magnitude of the 20-40 min excitatory responses was significantly different from baseline in NIC-60 d $\left(t_{(7)}=3.42, p<0.05\right)$ but not in NIC-1 d $\left(t_{(4)}=0.87, p>0.05\right)$, NIC-8 d $\left(t_{(5)}=0.89, p>0.05\right)$, yoked $\left(t_{(4)}=0.08, p>0.05\right)$, or SAL-60 d rats $\left(t_{(6)}=0.65, p>0.05\right)$. Stimulation of the ILCx induced potentiation of evoked spikes, which was NMDAdependent (Fig. 2E; 20-40 min after tetanic stimulation, magnitude $88 \pm 9 \% ; p>0.5)$, indicating induction of LTP at ILCxBNST synapses. No differences were observed between the control groups (no discrimination, no LTP). Detailed analysis of the discrimination rate for each rat in the NIC- 8 d group showed that only $50 \%$ of the rats had acquired nicotine IVSA. Interestingly, only these rats developed LTP in response to ILCx stimulation (Spearman correlation, $r=0.7421, p<0.01$ ). Saccharintrained animals showed a strong preference for the reinforced 
A

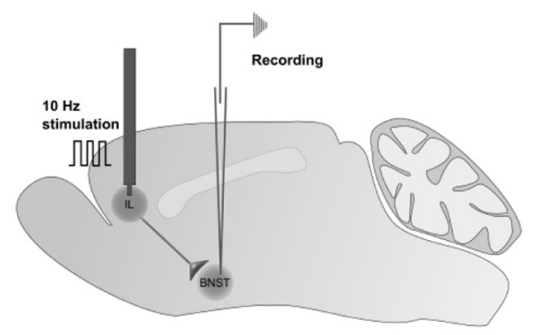

C
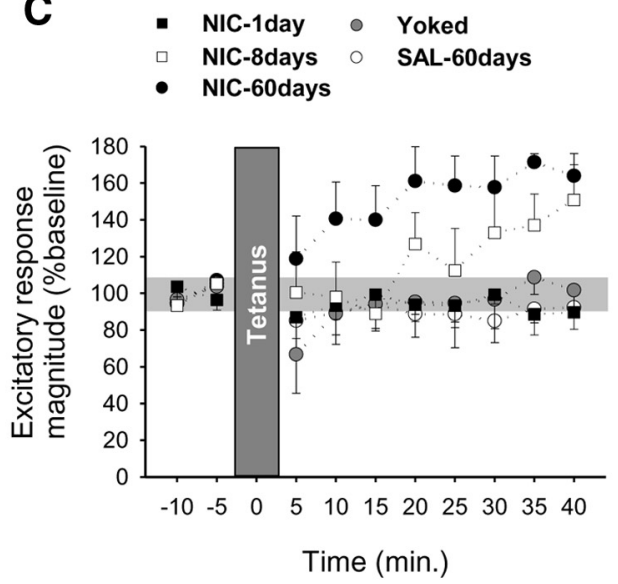

E $\quad$ NIC-60days $\circ$ NIC-60days + AP5

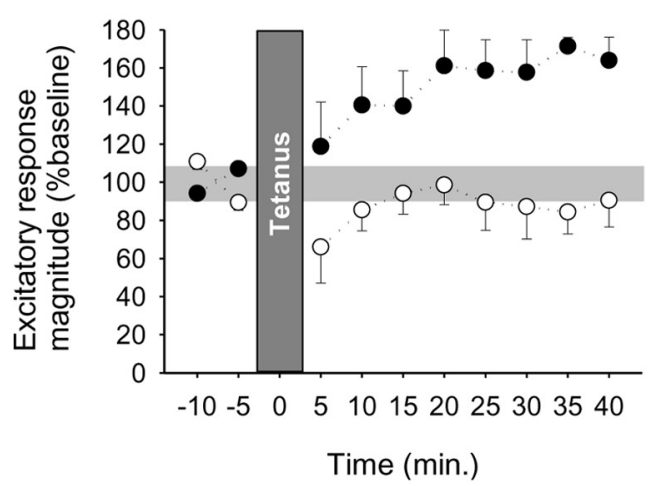

B

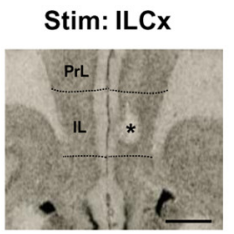

Rec: BNST

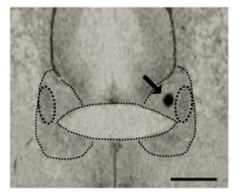

D
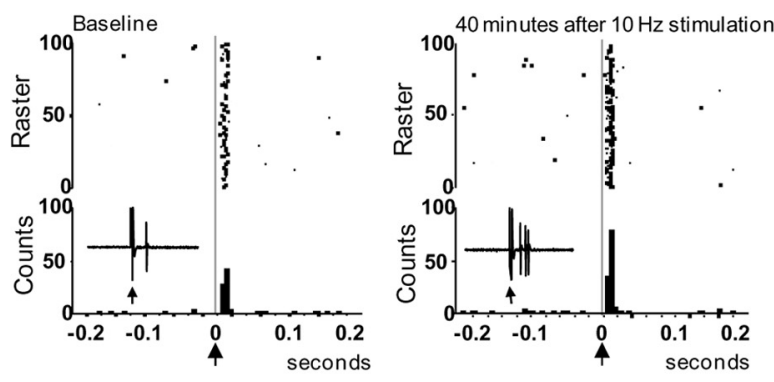

Figure 2. Effect of the $10 \mathrm{~Hz} \mathrm{ILCx}$ stimulation onto BNST neurons at different stages of nicotine acquisition and maintenance. $\boldsymbol{A}$, Stimulation and recording protocol. $\boldsymbol{B}$, Histological control of stimulation (ILCX, ${ }^{*}$ ) and recording (BNST, arrow) sites. Scale bar, $1 \mathrm{~mm}$. C, LTP seen in NIC-60 d rats but not in NIC-1 d, NIC-8 d, SAL-60 d, or yoked rats. D, Baseline and post-tetanic stimulation responses of ILCX-BNST projection neurons in NIC-60 d rats. Stimulus delivered at time $=0$ (arrow). Each histogram consists of 100 trials individually illustrated in the associated raster. Bin width, $5 \mathrm{~ms}$. $\boldsymbol{E}$, The $10 \mathrm{~Hz}$ ILCx stimulation induces NMDA-dependent LTP within the BNST. Microinjection of the NMDA antagonist AP5 (400 $\mu$ M, $60 \mathrm{nl}$ ) blocks the induction of LTP. Data are mean \pm SEM.

nose-poke (discrimination between active and inactive, $83.1 \%$ ). However, oral self-administration of saccharin did not induce synaptic changes within the BNST (excitatory response magnitude 20-40 min after tetanic stimulation, $129 \pm 33 \% ; p>0.5$ ). These data suggest that the acquisition of self-administration of nicotine, but not saccharin, produces experience-dependent modifications of ILCX-BNST synapses, which can be revealed by the stimulation of ILCx afferents.

\section{Persistence of the synaptic changes within the BNST}

To determine the persistence of the observed synaptic changes, we either imposed abstinence or performed extinction training in rats previously exposed to nicotine self-administration (Fig. $3 A$ ). Across extinction training sessions (no drug, no cue), active responses declined $\left(t_{(5)}=3.97, p=0.02\right)$, whereas responses at the inactive hole remained stable (data not shown). Extinction train- ing suppressed LTP in response to $10 \mathrm{~Hz}$ ILCx stimulation, which instead induced long-term depression after abstinence (Fig. 3B; two-way ANOVA, $F_{(9,74)}=4.91, p<0.0001,20-40 \mathrm{~min}$; Abst, $t_{(5)}=2.94, p<0.05$; Ext, $\left.t_{(4)}=14.84, p<0.001\right)$, indicating that the synaptic alteration is resistant to a passive drug-free period but sensitive to new learning.

\section{BNST LTP in response to ILCx $10 \mathrm{~Hz}$ stimulation is CB1 receptor-dependent}

Because the endocannabinoid system plays an important role in nicotine reward (Simonnet et al., 2013) and in the modulation of synaptic plasticity in the BNST (Massi et al., 2008; Puente et al., 2011), we investigated the ability of the CB1 receptor to control the potentiation of ILCX-BNST excitatory synapses. Induction of LTP in the BNST of NIC-60 d rats was blocked by peripheral injection of the CB1 antagonists (excitatory response magnitude 
A

$\triangle$ Abstinence $\triangle$ Extinction

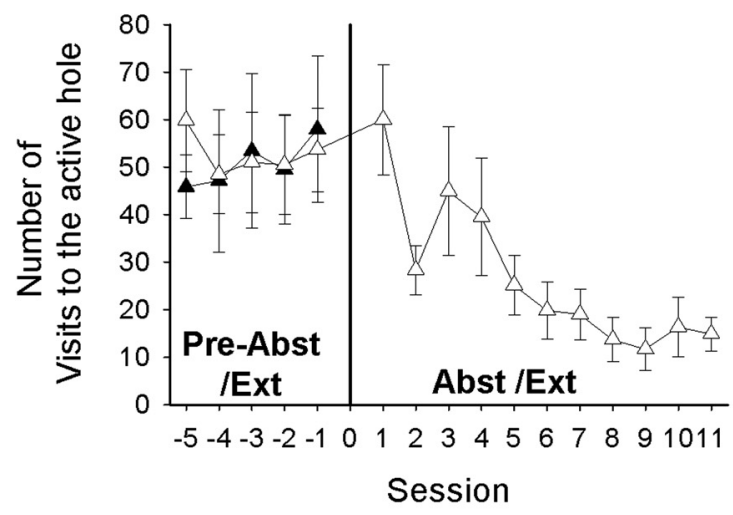

B

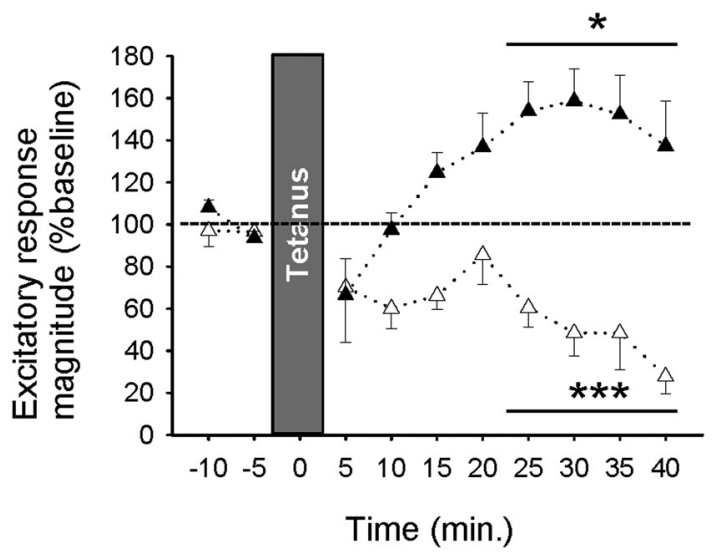

Figure 3. Effect of the $10 \mathrm{~Hz} \mathrm{ILCx}$ stimulation onto BNST neurons after abstinence versus extinction. $A$, Decreasing active responses during extinction training. $\boldsymbol{B}$, Extinction (Ext, $n=6$ ) but not abstinence (Abst, $n=7$ ) blocks LTP. ${ }^{*} p<0.05$. ${ }^{* * *} p<0.001$. Data are mean \pm SEM.

A

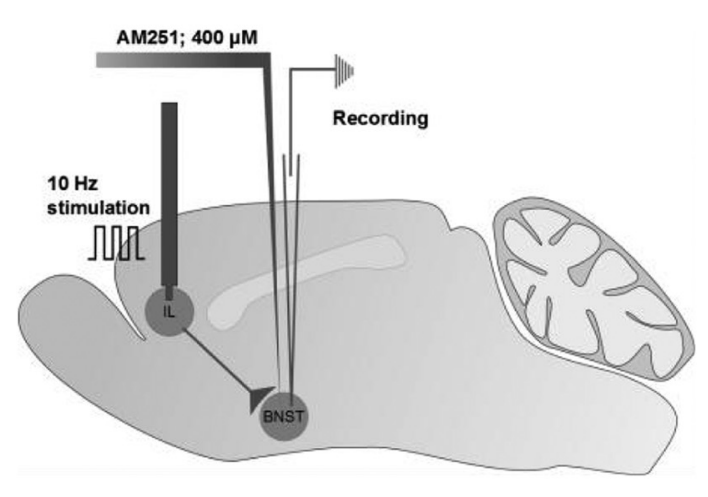

B

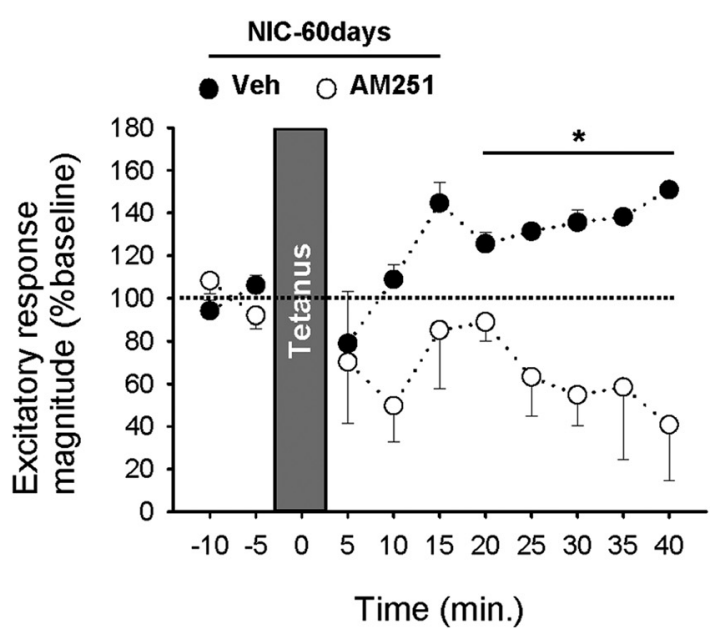

Figure 4. In Nic-60 d rats, $10 \mathrm{~Hz}$ stimulation of ILCx inputs evokes LTP that is CB1 receptor mediated. A, In vivo ILCx stimulation (1 min, $10 \mathrm{~Hz})$ in anesthetized rats. CB1 antagonist AM251 (60 nl, $400 \mu \mathrm{M}$ ) or vehicle was infused into the BNST before stimulation. B, AM251 blocks electrically induced LTP in NIC-60 d rats (Veh, $n=5 ;$ AM251, $n=5)$. ${ }^{*} p<0.05$. Data are mean \pm SEM.

20-40 min: Veh, $131.6 \pm 4.4 \%$; AM251, $78 \pm 10 \%, p>0.05$ O-2050, $129 \pm 33 \% ; p>0.5)$. More specifically, LTP induction was blocked after infusion of AM251 within the BNST (Fig. $4 A, B$; two-way ANOVA, $F_{(1,48)}=31.33, p<0.0001,20-40 \mathrm{~min}$; Veh, $131 \pm 4 \%$, AM251, $64 \pm 13 \% ; p>0.05)$. This suggests that nicotine self-administration permits the induction of CB1dependent LTP at BNST synapses in response to $10 \mathrm{~Hz}$ stimulation of ILCx afferents.

\section{Effect of ILCx stimulation on nicotine self-administration and cue-induced nicotine seeking}

Next, the challenging question was whether electrical stimulation of the ILCx may alter future operant behaviors for nicotine (Fig. $5 A$, timeline) and whether it could be prevented by local microinjection of AM251.

Our results showed that neither $10 \mathrm{~Hz}$ stimulation of the ILCx nor the AM251 pretreatment altered operant responding for nicotine; all groups respond by a similar number of visits to the active hole (Fig. 5B; ANOVA, $p>0.05$ ). Moreover, nicotine intake was similar in all groups whatever the session considered (Fig. 5C; ANOVA, $p>0.05$ ). However, after extended training, the stimulation altered responding at the active hole during timeout (Fig. $5 D$; ANOVA, $F_{(3,108)}=3.75, p<0.01$ ). Rats that underwent stimulation with vehicle pretreatment showed a progressive increase in responses (vs Session $1, p<0.01$ ). This was absent in sham stimulated rats and completely prevented by BNST CB1 receptor antagonism in stimulated animals (Stim Veh vs Stim AM251, $p<0.01$ ). No differences were observed between these two groups in general activity (stim + Veh, $1241 \pm 106$ beam breaks; stim $\times$ AM251, $1254 \pm 140$ beam breaks; Student's $t$ test, $\left.t_{(21)}=0.08, p>0.05\right)$. These data suggest that the stimulation increased responding for the cue light.

To test this hypothesis, all groups were tested for cue-induced reinstatement (Fig. 5E). ANOVA revealed a significant effect of the cue presentation compared with no cue presentation $\left(F_{(1,27)}=\right.$ $20.48, p<0.001)$. The no cue period resulted in a low number of visits to the active hole for all groups (interaction $F_{(1,27)}=2.42$, $p>0.05)$. Stimulation of the ILCx increased the cue-induced visits to the active hole (main effect stimulation, $F_{(1,27)}=5.50$, $p<0.02$ ). There was no significant interaction stimulation $X$ CB1 antagonist treatment (ANOVA, $p>0.05$ ), suggesting that AM251 tends to decrease visits to the active hole in both stimu- 


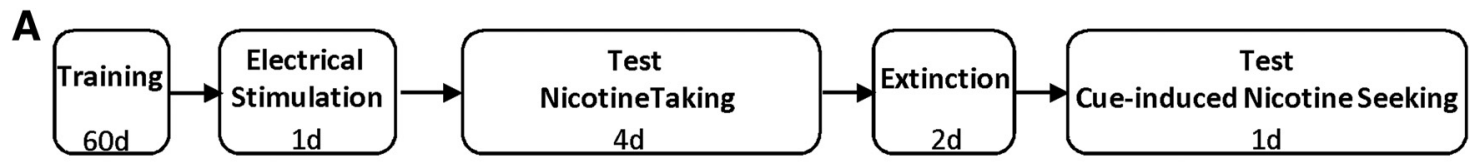

\section{Test NicotineTaking (nicotine and cue light available)}

B

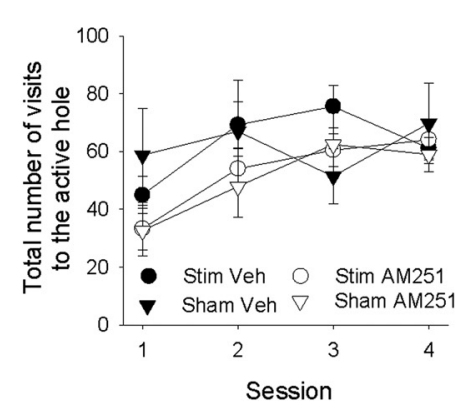

C

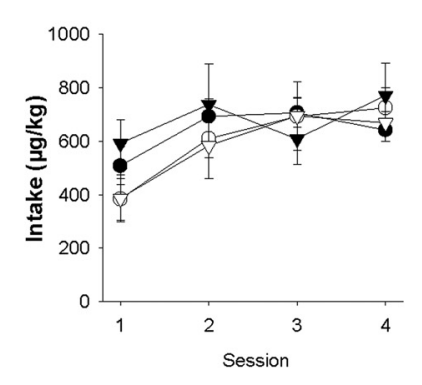

D

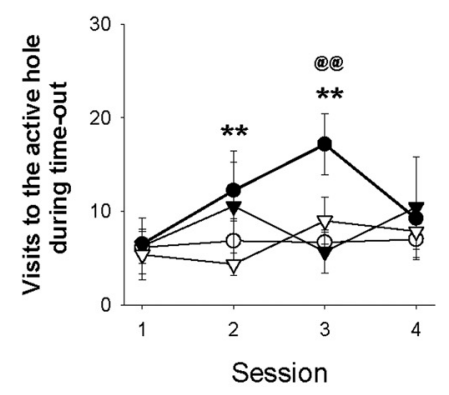

Test cue-induced Nicotine Seeking (no nicotine but cue light available)

E

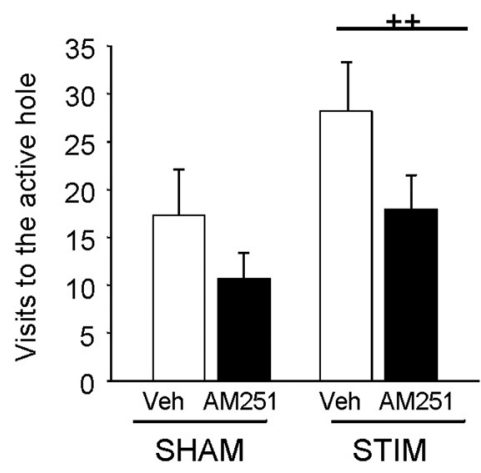

Figure 5. Effects of $10 \mathrm{~Hz}$ ILCx stimulation on active responding during nicotine self-administration and on cue-induced reinstatement. $A$, Timeline of experiment. Rats were: (1) trained for nicotine self-administration (60 d), (2) anesthetized, received ILCx electrical stimulation $24 \mathrm{~h}$ after the last session (1 d) and CB1 antagonist pretreatment (Veh or AM251, $400 \mu \mathrm{M} ; 60 \mathrm{nl}),(3)$ tested for nicotine taking ( $4 \mathrm{~d})$, (4) trained for extinction (2 d), and (5) tested for cue-induced nicotine seeking. Effects of ILCX and sham stimulation in vehicle and AM251-treated rats on the following: $\boldsymbol{B}$, Total number of visits in active hole during the whole session. $\boldsymbol{C}$, Total nicotine intake over the whole session. $\boldsymbol{D}$, Total number of visits in active hole during time-out. $\boldsymbol{E}$, Total number of visits in the active hole during the cue-induced reinstatement period. Post hoc active hole Veh Session 1 versus Session 2 and Veh Session 1 versus Session $3,{ }^{* *} p<0.01$. ${ }^{@} p<0.01$, main effect stimulation versus sham stimulation. ${ }^{++} p<0.02 . \boldsymbol{B}-\boldsymbol{D}$, Data are mean \pm SEM. $\boldsymbol{E}$, Data are mean + SEM.

lated and nonstimulated rats. The level of responding in the inactive hole was not altered by cue presentation (ANOVA, $p>$ $0.05)$.

\section{Discussion}

The aim of the present study was to determine whether acquisition of nicotine taking, and then cue-induced nicotine seeking, involved cellular adaptations at ILCx-BNST synapses. To reveal alterations in this neuronal circuit, we applied electrical stimulation to the ILCx at frequencies similar to physiological activation. Our results indicate that $60 \mathrm{~d}$ of nicotine self-administration facilitates the induction of LTP in the BNST in response to $10 \mathrm{~Hz}$ ILCX stimulation. The occurrence of this stimulation-induced LTP correlates with the degree of acquisition of selfadministration and is dependent on BNST CB1 receptors. In addition, it resists $30 \mathrm{~d}$ of forced abstinence. Finally, $10 \mathrm{~Hz}$ stimulation increased time-out responding during nicotine selfadministration as well as cue-induced nicotine seeking. Results suggest that blockade of BNST CB1 receptors reduced aberrant responding.
Electrical stimulation of the ILCx at $10 \mathrm{~Hz}$ mimics the physiological activation observed during goal-oriented behaviors (Jackson et al., 2001). This physiologically relevant stimulation triggered neuroplastic changes in BNST neurons only in rats that had acquired nicotine self-administration behavior, but not after passive exposure to nicotine. We propose that synaptic plasticity is the cellular mechanism underlying the change in responsiveness of BNST neurons to prefrontal inputs after $10 \mathrm{~Hz}$ ILCx stimulation in NIC-60 d rats. This conclusion is supported by our results showing that the mechanism depends on the activation of NMDA receptors. Alternative mechanisms for evoked spike potentiation in the BNST could be a change in intrinsic excitability of BNST neurons after extended training with nicotine or a change in the level of tonic activity at inhibitory inputs. However, these scenarios are unlikely as the reduction in threshold current for spike initiation in the BNST of NIC-60 d rats is not associated with changes in the basal activity of BNST neurons (Caille et al., 2009). Further work will be needed to determine whether increased spike firing in response to $10 \mathrm{~Hz}$ stimulation in NIC-60 d 
rats is the result of the enhancement of synaptic strength or a change in intrinsic excitability of the BNST neurons.

Acquisition of self-administration of nicotine, but not of a natural reinforcer, promotes cellular adaptations at ILCx-BNST excitatory synapses. Rats that did not respond for nicotine (saline or saccharin) and rats that did not meet the learning criterion (yoked or NIC-1 d) did not show LTP in response to electrical stimulation of the ILCx. Importantly, in the NIC-8 d group, we report a correlation between the development of a preference for the cue and nicotine-paired hole, and the emergence of synaptic potentiation in the ILCx-BNST pathway. Rats that selfadministered the drug by chance did not show facilitation of LTP induction, whereas all rats with extended training did (Kasanetz et al., 2013). Our findings suggest that the ILCx-BNST pathway is involved in aberrant stimulus-response behavior and might contribute to the established habitual behaviors observed in drug addiction (Everitt and Robbins, 2005). The development of habits is involved in the transition from drug use to drug abuse; therefore, an interesting investigation would be to examine how the stimulus-response association (Zapata et al., 2010; Smith et al., 2012) controls nicotine seeking as well as the neuroadaptations at ILCX-BNST synapses.

Smoking-related cues have increased significance in smokers (Rose and Corrigall, 1997) and in animal models of nicotine addiction (Chaudhri et al., 2006). We show here that LTP induction and suppression are both directly linked to the learning of a specific relationship between motor actions and cue-associated reinforcement, rather than to the presence (yoked condition) or absence (extinction condition) of the drug. Thus, although nicotine enhances the reinforcing properties of discrete and contextual stimuli (Palmatier et al., 2007), reexposing rats with a long history of nicotine taking to such stimuli may reactivate the strengthened projections of the ILCx (Bossert et al., 2011) and subsequently induce nicotine seeking. In accordance with this idea, we show here that $10 \mathrm{~Hz}$ stimulation of the ILCx promotes excessive visits to the nicotine- and cue-paired nose-poke hole while the drug is not available.

Much evidence implicates the BNST in stress and anxiety (Glangetas et al., 2013; Jennings et al., 2013). Therefore, an additional explanation of our results might be that the induction of LTP and the increase in responding during time-out are both produced by the experience of the negative/anxiogenic effects of nicotine (George et al., 2007). Consistent with this hypothesis, previous studies have demonstrated that extended access to nicotine produced escalation of nicotine intake only when animals experienced intermittent withdrawal periods (O'Dell and Koob, 2007; Cohen et al., 2012). In our experiment, the ILCx stimulation protocol (Fig. 5A) introduced a period of abstinence, which may have subsequently led to the development of a nicotine withdrawal-induced negative drive. Therefore, one cannot discard the possibility that the increase in active responding during the time-out period is the expression of increased incentive value of nicotine acting as a negative reinforcer (Koob and Le Moal, 2001) and that this increase modified nicotine intake.

In the present study, we have demonstrated that extinction training facilitates inhibition of the ILCx-BNST pathway, whereas the synaptic strengthening remains intact after forced abstinence. The extinction protocol used in this study resulted in an average of $17.2 \mathrm{~d}$ to meet extinction criteria. However, the forced abstinence period was $30 \mathrm{~d}$, which might suggest that LTP found after abstinence is the result of an incubation effect (Grimm et al., 2001), rather than the persistence of synaptic mod- ifications through a drug-free period. We have not subjected rats to various durations of forced abstinence to rule out the incubation effect of LTP over time, but such an effect is unlikely as the period of extinction training ranged from 11 to $27 \mathrm{~d}$, and all rats showed induction of long-term depression.

In rats trained to self-administer nicotine for $60 \mathrm{~d}$, the induction of LTP in response to $10 \mathrm{~Hz}$ stimulation of ILCx afferents depends on CB1 receptors expressed within the BNST. Notably, we can discard the possibility that this was a consequence of $\mathrm{CB} 1$ receptor inverse agonist properties of AM251 because the LTP was also blocked by the administration of O-2050, a CB1 receptor neutral antagonist (Dubreucq et al., 2013). In naive rats, ex vivo electrophysiological studies support the existence of endocannabinoiddependent forms of synaptic plasticity in the BNST (Puente et al., 2011). Interestingly, nicotine self-administration increases 2-arachidonoyl glycerol as well as anandamide levels in the VTA of behaving animals (Buczynski et al., 2013). Although the increased VTA anandamide levels correlate with the volitional nature of drug exposure, the specific blockade of $\mathrm{CB} 1$ receptors in the VTA strongly decreases nicotine self-administration in rats (Simonnet et al., 2013). One can therefore propose that, similar to the VTA mechanisms, chronic nicotine consumption might lead to changes in endocannabinoid tone within the BNST and contribute to cellular adaptations at ILCx-BNST synapses. However, the nature of the endocannabinoid involved here remains unknown.

Peripheral administration of a CB1 antagonist strongly decreases nicotine self-administration (Cohen et al., 2002; Shoaib, 2008; Simonnet et al., 2013), suggesting that stimulation of CB1 receptors is important for nicotine reinforcement. In the present study, AM251 injected within the BNST selectively blocked excessive responding during time-out but did not change nicotine intake. In line with this observation, previous studies have indicated that the BNST is involved in cue-induced drug seeking rather than in the control of drug taking. For instance, increased activity of neurons in the BNST is associated with increased drug seeking during protracted withdrawal and in opiate-induced conditioned place preference (Harris and Aston-Jones, 2003). Moreover, inactivation of the BNST specifically blocks cocaine seeking elicited by drug-paired cues (Buffalari and See, 2011). Together, these findings strongly support the hypothesis that extended training to self-administer nicotine and sustained activation of the ILCx induce CB1 receptor-dependent neuroplastic changes in the BNST that might be involved in the stimulus tracking behavior paired with nicotine taking (Palmatier et al., 2013; Paolone et al., 2013).

In conclusion, our findings indicate that acquisition of nicotine self-administration allows the induction of evoked-spike potentiation in the BNST in response to $10 \mathrm{~Hz}$ stimulation of ILCx afferents. This neuroadaptation resists abstinence and seems to contribute to a maladaptive stimulus-response behavior controlled by CB1 receptors (Marsicano et al., 2002) in the BNST, suggesting that it might be responsible for vulnerability to cueinduced relapse. Further investigation will be needed to fully elucidate the key role of the ILCx-BNST pathway in the attribution of salience to nicotine-paired cues.

\section{References}

Bossert JM, Stern AL, Theberge FR, Cifani C, Koya E, Hope BT, Shaham Y (2011) Ventral medial prefrontal cortex neuronal ensembles mediate context-induced relapse to heroin. Nat Neurosci 14:420-422. CrossRef Medline

Buczynski MW, Polis IY, Parsons LH (2013) The volitional nature of nico- 
tine exposure alters anandamide and oleoylethanolamide levels in the ventral tegmental area. Neuropsychopharmacology 38:574-584. CrossRef Medline

Buffalari DM, See RE (2011) Inactivation of the bed nucleus of the stria terminalis in an animal model of relapse: effects on conditioned cueinduced reinstatement and its enhancement by yohimbine. Psychopharmacology (Berl) 213:19-27. CrossRef Medline

Caillé S, Guillem K, Cador M, Manzoni O, Georges F (2009) Voluntary nicotine consumption triggers in vivo potentiation of cortical excitatory drives to midbrain dopaminergic neurons. J Neurosci 29:10410-10415. CrossRef Medline

Carboni E, Rolando MT, Silvagni A, Di Chiara G (2000) Increase of dialysate dopamine in the bed nucleus of stria terminalis by clozapine and related neuroleptics. Neuropsychopharmacology 22:140-147. CrossRef Medline

Castañé A, Valjent E, Ledent C, Parmentier M, Maldonado R, Valverde O (2002) Lack of CB1 cannabinoid receptors modifies nicotine behavioural responses, but not nicotine abstinence. Neuropharmacology 43:857-867. CrossRef Medline

Chaudhri N, Caggiula AR, Donny EC, Palmatier MI, Liu X, Sved AF (2006) Complex interactions between nicotine and nonpharmacological stimuli reveal multiple roles for nicotine in reinforcement. Psychopharmacology (Berl) 184:353-366. CrossRef Medline

Cohen A, Koob GF, George O (2012) Robust escalation of nicotine intake with extended access to nicotine self-administration and intermittent periods of abstinence. Neuropsychopharmacology 37:2153-2160. CrossRef Medline

Cohen C, Perrault G, Voltz C, Steinberg R, Soubrié P (2002) SR141716, a central cannabinoid $(\mathrm{CB}(1))$ receptor antagonist, blocks the motivational and dopamine-releasing effects of nicotine in rats. Behav Pharmacol 13: 451-463. CrossRef Medline

Cohen C, Perrault G, Griebel G, Soubrié P (2005) Nicotine-associated cues maintain nicotine-seeking behavior in rats several weeks after nicotine withdrawal: reversal by the cannabinoid (CB1) receptor antagonist, rimonabant (SR141716). Neuropsychopharmacology 30:145-155. CrossRef Medline

Deroche-Gamonet V, Belin D, Piazza PV (2004) Evidence for addiction-like behavior in the rat. Science 305:1014-1017. CrossRef Medline

Dubreucq S, Durand A, Matias I, Bénard G, Richard E, Soria-Gomez E, Glangetas C, Groc L, Wadleigh A, Massa F, Bartsch D, Marsicano G, Georges F, Chaouloff F (2013) Ventral tegmental area cannabinoid type-1 receptors control voluntary exercise performance. Biol Psychiatry 73:895-903. CrossRef Medline

Dumont EC, Mark GP, Mader S, Williams JT (2005) Self-administration enhances excitatory synaptic transmission in the bed nucleus of the stria terminalis. Nat Neurosci 8:413-414. CrossRef Medline

Everitt BJ, Robbins TW (2005) Neural systems of reinforcement for drug addiction: from actions to habits to compulsion. Nat Neurosci 8:14811489. CrossRef Medline

George O, Ghozland S, Azar MR, Cottone P, Zorrilla EP, Parsons LH, O'Dell LE, Richardson HN, Koob GF (2007) CRF-CRF1 system activation mediates withdrawal-induced increases in nicotine self-administration in nicotine-dependent rats. Proc Natl Acad Sci U S A 104:17198-17203. CrossRef Medline

Georges F, Aston-Jones G (2002) Activation of ventral tegmental area cells by the bed nucleus of the stria terminalis: a novel excitatory amino acid input to midbrain dopamine neurons. J Neurosci 22:5173-5187. Medline

Glangetas C, Girard D, Groc L, Marsicano G, Chaouloff F, Georges F (2013) Stress switches cannabinoid type-1 (CB1) receptor-dependent plasticity from LTD to LTP in the bed nucleus of the stria terminalis. J Neurosci 33:19657-19663. CrossRef Medline

Grimm JW, Hope BT, Wise RA, Shaham Y (2001) Neuroadaptation: incubation of cocaine craving after withdrawal. Nature 412:141-142. CrossRef Medline

Harris GC, Aston-Jones G (2003) Enhanced morphine preference following prolonged abstinence: association with increased Fos expression in the extended amygdala. Neuropsychopharmacology 28:292-299. CrossRef Medline

Jackson ME, Frost AS, Moghaddam B (2001) Stimulation of prefrontal cortex at physiologically relevant frequencies inhibits dopamine release in the nucleus accumbens. J Neurochem 78:920-923. CrossRef Medline

Jennings JH, Sparta DR, Stamatakis AM, Ung RL, Pleil KE, Kash TL, Stuber GD (2013) Distinct extended amygdala circuits for divergent motivational states. Nature 496:224-228. CrossRef Medline
Kasanetz F, Lafourcade M, Deroche-Gamonet V, Revest JM, Berson N, Balado E, Fiancette JF, Renault P, Piazza PV, Manzoni OJ (2013) Prefrontal synaptic markers of cocaine addiction-like behavior in rats. Mol Psychiatry 18:729-737. CrossRef Medline

Koob GF, Le Moal M (2001) Drug addiction, dysregulation of reward, and allostasis. Neuropsychopharmacology 24:97-129. CrossRef Medline

Krawczyk M, Mason X, DeBacker J, Sharma R, Normandeau CP, Hawken ER, Di Prospero C, Chiang C, Martinez A, Jones AA, Doudnikoff É, Caillé S, Bézard E, Georges F, Dumont ÉC (2013) D1 dopamine receptormediated LTP at GABA synapses encodes motivation to self-administer cocaine in rats. J Neurosci 33:11960-11971. CrossRef Medline

Le Foll B, Forget B, Aubin HJ, Goldberg SR (2008) Blocking cannabinoid CB1 receptors for the treatment of nicotine dependence: insights from pre-clinical and clinical studies. Addict Biol 13:239-252. CrossRef Medline

Lüscher C, Malenka RC (2011) Drug-evoked synaptic plasticity in addiction: from molecular changes to circuit remodeling. Neuron 69:650-663. CrossRef Medline

Maldonado R, Valverde O, Berrendero F (2006) Involvement of the endocannabinoid system in drug addiction. Trends Neurosci 29:225-232. CrossRef Medline

Marsicano G, Wotjak CT, Azad SC, Bisogno T, Rammes G, Cascio MG, Hermann H, Tang J, Hofmann C, Zieglgänsberger W, Di Marzo V, Lutz B (2002) The endogenous cannabinoid system controls extinction of aversive memories. Nature 418:530-534. CrossRef Medline

Massi L, Elezgarai I, Puente N, Reguero L, Grandes P, Manzoni OJ, Georges F (2008) Cannabinoid receptors in the bed nucleus of the stria terminalis control cortical excitation of midbrain dopamine cells in vivo. J Neurosci 28:10496-10508. CrossRef Medline

Merritt LL, Martin BR, Walters C, Lichtman AH, Damaj MI (2008) The endogenous cannabinoid system modulates nicotine reward and dependence. J Pharmacol Exp Ther 326:483-492. CrossRef Medline

O'Dell LE, Koob GF (2007) 'Nicotine deprivation effect' in rats with intermittent 23-hour access to intravenous nicotine self-administration. Pharmacol Biochem Behav 86:346-353. CrossRef Medline

Palmatier MI, Liu X, Matteson GL, Donny EC, Caggiula AR, Sved AF (2007) Conditioned reinforcement in rats established with self-administered nicotine and enhanced by noncontingent nicotine. Psychopharmacology (Berl) 195:235-243. CrossRef Medline

Palmatier MI, Marks KR, Jones SA, Freeman KS, Wissman KM, Sheppard AB (2013) The effect of nicotine on sign-tracking and goal-tracking in a Pavlovian conditioned approach paradigm in rats. Psychopharmacology (Berl) 226:247-259. CrossRef Medline

Paolone G, Angelakos CC, Meyer PJ, Robinson TE, Sarter M (2013) Cholinergic control over attention in rats prone to attribute incentive salience to reward cues. J Neurosci 33:8321-8335. CrossRef Medline

Paxinos G, Watson C (1998) The rat brain in stereotaxic coordinates. San Diego: Academic.

Peters J, Kalivas PW, Quirk GJ (2009) Extinction circuits for fear and addiction overlap in prefrontal cortex. Learn Mem 16:279-288. CrossRef Medline

Puente N, Cui Y, Lassalle O, Lafourcade M, Georges F, Venance L, Grandes P, Manzoni OJ (2011) Polymodal activation of the endocannabinoid system in the extended amygdala. Nat Neurosci 14:1542-1547. CrossRef Medline

Rose JE, Corrigall WA (1997) Nicotine self-administration in animals and humans: similarities and differences. Psychopharmacology (Berl) 130: 28-40. CrossRef Medline

Shoaib M (2008) The cannabinoid antagonist AM251 attenuates nicotine self-administration and nicotine-seeking behaviour in rats. Neuropharmacology 54:438-444. CrossRef Medline

Simonnet A, Cador M, Caillé S (2012) Nicotine reinforcement is reduced by cannabinoid CB1 receptor blockade in the ventral tegmental area. Addict Biol 18:930-936. CrossRef Medline

Smith KS, Virkud A, Deisseroth K, Graybiel AM (2012) Reversible online control of habitual behavior by optogenetic perturbation of medial prefrontal cortex. Proc Natl Acad Sci U S A 109:18932-18937. CrossRef Medline

Zapata A, Minney VL, Shippenberg TS (2010) Shift from goal-directed to habitual cocaine seeking after prolonged experience in rats. J Neurosci 30:15457-15463. CrossRef Medline 